\title{
Developing cross-cultural competence of intending teachers under the conditions of the linguistic faculty
}

\author{
Ekaterina A. Kostina - Dzhafar Mallaev
}

DOI: 10.18355/XL.2019.12.04.14

\begin{abstract}
The development of cross-cultural competence is a complex task of professional education. The measurement of cross-cultural competence is difficult due to the fact that this competence develops throughout a person's life. It is, in fact, the competence of life. Therefore, we have set our goal to measure various aspects of the required competence, which will indicate a certain degree of its formation. To achieve the stated goal, we used the methods of questioning, testing, conversation, observation, expert evaluation, generalization of independent characteristics and interviewing of the faculty and administration of the University. In the course of experimental activity in the conditions of cross-cultural educational environment of the faculty of foreign languages of Novosibirsk State Pedagogical University the growth of indicators of formation of cross-cultural competence of students - future teachers of foreign language was revealed. Since the level of cross-cultural competence of students of the language faculty has shown a steady growth under the conditions of one faculty, we believe it is possible and necessary to create a cross-cultural educational environment in the whole University in order to form and develop cross-cultural competence, academic mobility and, as a result, improve professional competence of future teachers.
\end{abstract}

Key words: cross-cultural competence, cross-cultural educational environment, academic mobility, language education

\section{Introduction}

Cross-cultural competence of a foreign language teacher is a most important component of their professional competence. This fact explains great attention paid to the building and developing of cross-cultural competence in the educational process of the Faculty of foreign languages of the Novosibirsk State Pedagogical University.

A cross-cultural constituent is a significant element of academic mobility, which, in its turn, contributes invaluably to the development of professional competence of a teacher. R.B. Boyur believes that academic mobility is an inherent part of existence of intellectual potential ${ }^{1}$. Thus the notions of "cross-cultural competence" and "academic mobility" can be considered interdependent and interconnected.

The principle dominants of academic mobility in the cross-cultural educational environment at the language faculty can $\mathrm{be}^{2}$ :

\footnotetext{
${ }^{1}$ Boyur, R.B. Exchange of competences and guidance papers as mechanisms to manage quality in education. Reference date 30.03.2019. In: Net journal "Hoppocentaur". (In Russian). URL: http://www.circleplus.ru/content/communicarium/projects/7.

2 The same.
}

XLinguae, Volume 12, Issue 4, October 2019, ISSN 1337-8384, eISSN 2453-711X 
1) creation of cross-cultural space for adaptation and comfortable psychological condition of foreign students;

2) formation of skills of cross-cultural communication, activation of intercultural links, development, interaction, interpenetration of cultures;

3 ) repletion of wants to learning a language and to regular language training in the process of mutual cultural activity;

4) acquisition of knowledge in the sphere of national cultures through mutual classes, visiting theatres, museums, exhibitions, and concerts.

Development of cross-cultural competence raises the knowledge of cultures, builds skills of intercultural interaction, which allows perceiving and understanding properly the specificity of another culture and thus simplifying communication process and improving efficiency of a professional activity as a whole (Shirobokov S.N. 2012).

Following the definition of T.A. Kolosovskaya (Kolosovskaya T.A. 2010) we understand cross-cultural competence as an integral personality quality including knowledge of distinctive features of the other culture, skills to interpret information from the other culture, experience of communicative activity, and professionally important personality qualities (empathy and tolerance).

To cope with the task of building and developing cross-cultural competence one should take into account the abstract theorem on cross-culturalism as an important element of professionalism. Assuming this, students of different majors should be able to work culturally diverse people, be tolerant to them, realize human distinction, and contribute to cultural pluralism in the society (Dmitriev G.D. 1999).

Today the necessity of creating cross-cultural environment at all educational levels has become imminent.

Cross-cultural environment reveals the uniqueness of a personality nations, ensures rising of their best mental characteristics and governs cultural and civilized ways of communication (Šmajs J. 2016) leading to national harmony and peaceful life of the community. Intercultural communication and integration of different cultures values in the cross-cultural environment give birth to a new philosophy of life of at individual (Pushkarev Y.V., Pushkareva E.A. 2017) and community as a whole, bringing them to stability, harmony, and understanding.

The main characteristics of a cross-cultural educational environment is its tolerance focused on humanization of a pedagogical process, namely, on obeying the principle of mutual respect in cooperative activity of the process participants.

In institutions of professional training cross-cultural educational environment plays a special role as it is here where the making of a specialist, the building of professional competences as well as cultural enrichment of a young person's personality takes place. Cross-cultural tolerant environment in the system of professional training contributes to professional development of a personality (Korabliova A.A. 2014).

Successful cross-cultural development of a professional depends on the following conditions:

1) sociocultural background of an applicant. It includes: their attitude to the world, themselves, people (Pushkarev Y.V., Pushkareva E.A. 2016); knowledge of national cultures and culture of international communication; experience of international communication and behavior in polycultural environment.

2) intercultural education at University, which implies teaching students the rules of international communication; involving students into ethnic self-education; ensuring the students to acquire the values of national cultures at personal and professional levels (Kondratyeva T.N. 2015).

Cross-culturalness is an important element of professionalism, and forming cross-culturalness as a personal quality of a professional is impossible if they do not know a foreign language and the culture of native speakers of this language. The goal 
of teaching a foreign language in modern high school can be formulated like this: developing readiness to function as a subject in an international professional community, where a foreign language acts both as a means of gaining extra professional knowledge and a means of solving professional problems (Sidorenko T.V., Rybushkina S.V. 2015.). In this connection the goal of learning a foreign language is integration into an international academic, professional, scientific and business community, and foreign language here is of key significance.

Including academic mobility as an obligatory component into the process of training a qualified specialist assures acquisition by students of realities of another country, broadening of students' general outlook, introduction to the world culture, getting to know the way education is organized abroad and a firm motivation to learn a foreign language as a tool to gain professionalism.

From the perspective point of view, within a framework of a cross-cultural aspect academic mobility will contribute to establishing and developing intercultural dialogue with spreading a language and cultural values. Cultural mobility assures an innovative approach to solving educational problems basing on the principle of humanism in a social environment (Kozlova N.A. 2012). Academic mobility organized on the basis of the cross-cultural approach can help to take a new look at the following fields of potential conflicts in the society:

- $\quad$ racism and discrimination;

- $\quad$ influence of culture on education;

- $\quad$ diversity of languages and motivation of Russian students to learn them.

In other words, cross-cultural education in the XXI century is upbringing of global spirit and tolerance. And this requires the experience of contacting another culture, another way of life. As a result of interaction of representatives of different cultures (Kostina, E.A., Hackett-Jones A.V., Bagramova, N.V. 2017) when training foreign students in home institutions takes place in standard academic groups, it is appropriate to say that cross-cultural academic environment is being created (Khoroshilova S.P., Kostina E.A. 2016) and cross-cultural competence of foreign and home students is being built and developed. As such, artificially created cross-cultural environment gives a chance to representatives of different ethnic groups to learn to respect norms, values, religion of one another (Mardakhaev L.V., Egorychev A.M., Varlamova E.Yu., Kostina E.A. 2018), setting, in this way, the background for fruitful effective mutual activity.

\section{Materials and Methods}

\section{Objectives}

To achieve the goal of developing students' cross-cultural competence under the conditions of cross-cultural educational environment built up at the faculty of foreign languages and students' participation in the process of real academic mobility, the following tasks of experimental work were allotted:

1. To raise the students' level of cultural and local knowledge;

2. To form students' cross-cultural skills;

3. To form students' readiness to academic mobility.

\section{Methods}

The investigation methods are testing, questioning, and expert assessment. 


\section{Sample}

Since 2012 we have been monitoring the $2^{\text {nd }}$ and $3^{\text {rd }}$-year full-time, intraextramural and part-time students of the faculty of foreign languages of Novosibirsk State Pedagogical University. The choice of the $2^{\text {nd }}$ and $3^{\text {rd }}$-year-students is explained by the fact that at this stage of their educational professional programmes the students begin studying the subjects of cross-cultural character (Linguistic and Cultural Studies, Culture of the Countries under Study, Geography of the Countries under Study, History of the Countries under Study, etc.), one of the goals to study these subjects is building and developing cross-cultural competence of intended graduates of the faculty of foreign languages. The number of students involved in the experimental process totals 449 persons.

\section{Results}

The level of cross-cultural knowledge of the students was assessed through computer tests. The compared results of pre-experimental and post-experimental testing are demonstrated on diagram 1 (Figure 1):

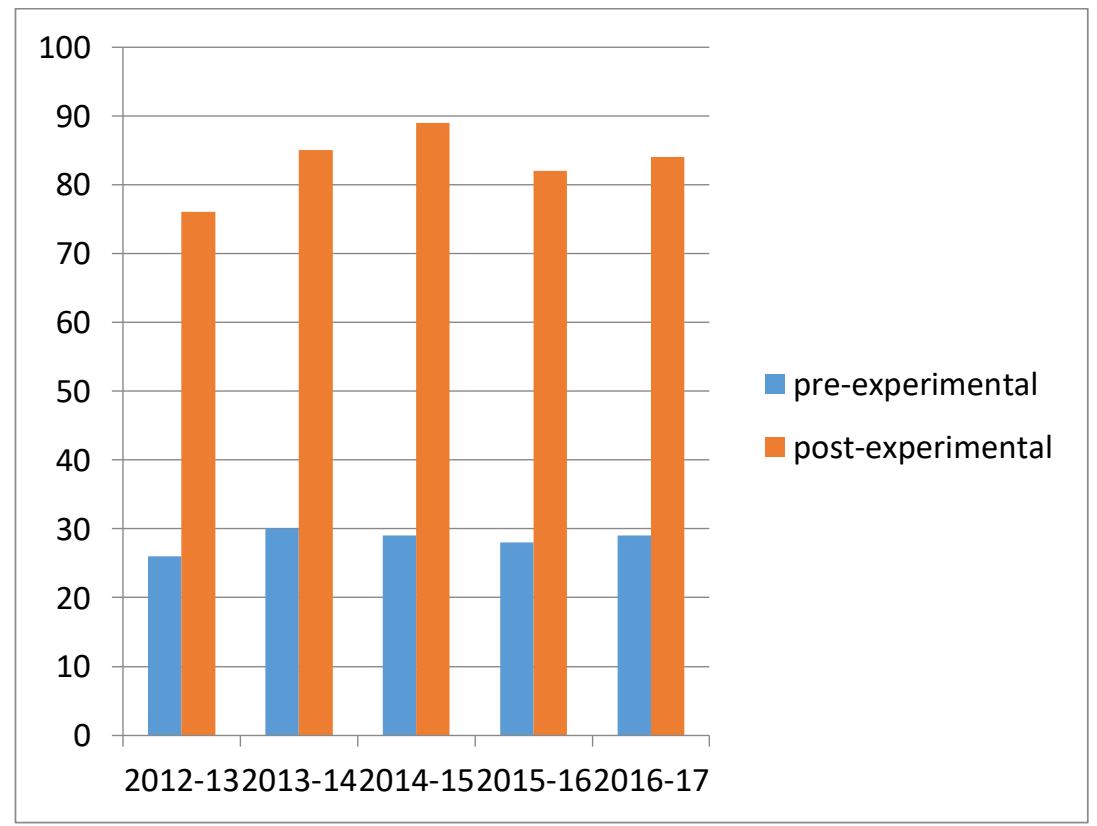

Figure 1: Comparison of the level of the respondents' cross-cultural knowledge at the experimental stage

The result of comparing the level of the respondents' cross-cultural knowledge gained in the process of pre-experimental and post-experimental testing verified with the help of Student t-test ${ }^{3}$ states that the gained empirical value $t$ (24.6) is in the field of significance, which testifies to a considerable difference of the results of the experimental groups.

${ }^{3}$ Student t-test. [On-line resource]. Reference date 19.07.2017. URL: http://www.psycholok.ru/statistics/student/. 
With the aim of analyzing the organization of the process of students' academic mobility at the Faculty of foreign languages (FFL) of Novosibirsk State Pedagogical University (NSPU) we conducted questioning of the 300 students who had studied in foreign educational institutions.

On the basis of the results of the questionnaire survey we can portray a student of the Faculty of foreign languages of Novosibirsk State Pedagogical University.

\section{In most cases}

- $\quad$ they are twenty years old;

- they consider academic mobility a necessary component of education at university;

- they believe that state funding would increase the number of students participating in the process of academic mobility;

- $\quad$ they receive financial help from their parents for studying abroad;

- $\quad$ they studied in China of England;

- they got the information on studying abroad at the faculty of foreign languages of Novosibirsk state pedagogical university;

- they went to study exactly at this institution for a period up to one month to master the foreign language proficiency level under the attractive conditions created by the host organization;

- the length of studying was determined by the terms of the agreement between the partner organizations;

- without feeling discomfort in another culture environment, nevertheless, they think, it is necessary to organize at their home university special classes with the aim to prepare students for staying in a society with other culture and mentality;

- without unique problems they communicated in the language under study with the representatives of another culture;

- they got to know the peculiarities of a local national culture in the process of communicating with students of the host country in their free time;

- they consider it important to be cross-culturally competent, realizing that cross-cultural competence is being built in the process of academic mobility;

- they believe that studying abroad improves foreign language proficiency and broadens the mind thanks to gaining international experience.

It appears that the conducted questionnaire justified the necessity and correctness of the international activity undertaken at the Faculty of foreign languages of Novosibirsk State Pedagogical University, taking into account that within this activity the process of academic mobility of students is being organized.

The level of students' cross-cultural skills and knowledge was assessed by 97 experts representing educational institutions of different levels of the Russian Federation and near and far abroad countries.

The compared results of the opening evaluation and final experts' evaluation one can see on diagram 2 (Figure 2): 


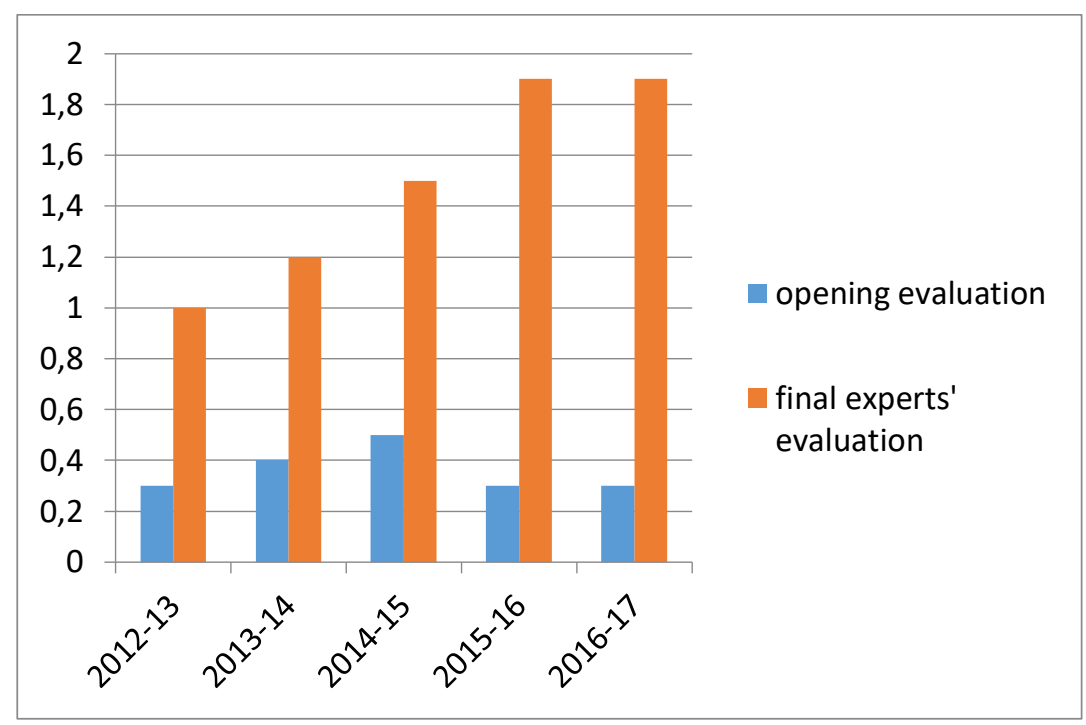

Figure 2: Students' cross-cultural competence level

The result of comparing these parameters characterizing the level of crosscultural competence of the respondents and their readiness for academic mobility gained in the process of opening and final evaluation verified with the help of Student t-test ${ }^{4}$ states that the gained empirical value $t(6.3)$ is in the field of significance, which testifies to a considerable difference of the results of the experimental groups.

\section{Conclusion}

As it follows from the results of the research, obvious and statistically valid is the fact of improving the respondents' level of cultural and country studies knowledge and, consequently, of the level of their cross-cultural competence resulting from their doing the academic courses (Culture-oriented linguistics and country studies, Country studies, Culture of the language-under-studies countries, History and geography of the language-under-studies countries, etc.) of the effective curricula of the bachelor programme Pedagogical education.

The level of readiness of the students for academic mobility under the conditions of cross-cultural educational environment of the higher educational institution (Novosibirsk State Pedagogical University) can be defined as admissible (average), coming close to the optimal (high) level.

The positive results gained on the basis of one faculty testify of a possibility and necessity to build cross-cultural educational environment at the University as a whole for developing cross-cultural competence of students in the process of professional pedagogical training.

${ }^{4}$ The same as 3 . 


\section{Bibliographic references}

DMITRIEV, G.D. 1999. Multicultural education. M., 208 p. (In Russian).

KHOROSHILOVA, S.P. - KOSTINA, E.A. 2016. Cross-cultural study of the impact of short-term language courses abroad on language acquisition. In: Novosibirsk State Pedagogical University Bulletin, n. 4, pp. 108-118. URL: https://elibrary.ru/item.asp?id=26583956.

KONDRATYEVA, T.N. 2015. Education of culture of interethnic communication of students of higher educational institution on the basis of ethno-pedagogical approach. Medicine and education in Siberia, n. 4, pp. 4. (In Russian). Available online: https://elibrary.ru/item.asp?id=24847710

KOLOSOVSKAYA, T. 2010. Formation of cross-cultural competence of future teachers: monograph. Shadrinsk, 200 p. (In Russian) Available online: https://elibrary.ru/item.asp?id=20107093

KORABLIOVA, A.A. 2014. Essence of the category of "tolerant educational environment" in the system of the most adjacent. In: Yaroslavl pedagogical Bulletin , n. 1 , pp. 44-48. (In Russian). Available online: https://elibrary.ru/item.asp?id=21361672.

KOSTINA, E.A. - HACKETT-JONES, A.V. - BAGRAMOVA, N.V. 2017. The impact of interlanguage on students' bilingual behaviour during the process of acquiring a foreign language. In: Novosibirsk State Pedagogical University Bulletin, n. 4, pp. 93-107. Available online: https://elibrary.ru/item.asp?id=29962696.

KOZLOVA, N.A. 2012. Academic mobility: the nature of the vectors and strategy of development: monograph. SPb., 88 p. (In Russian) Available online: https://elibrary.ru/item.asp?id=28132952.

MARDAKHAEV, L.V. - EGORYCHEV, A.M. - VARLAMOVA, E.Yu. KOSTINA, E.A. 2018. Development of linguo-cultural personality of future teachers within the educational environment of higher educational institutions. Novosibirsk State Pedagogical University Bulletin, n. 4, pp. 204-216. (In Russian). Available online: https://elibrary.ru/item.asp?id=35605579.

SMAJS, J. 2016. On the principle of evolutionary ontology. In: Novosibirsk State Pedagogical University Bulletin, n. 1, pp. 78-86. (In Russian) Available online: http://sciforedu.ru/article/1680.

PUSHKAREV, Y.V. - PUSHKAREVA, E.A. 2017 The concept of intellectual potential development: the main dimensions and bases within the context of lifelong education (review). In: Novosibirsk State Pedagogical University Bulletin, n. 3, pp. 140-156. (In Russian). Available online: https://elibrary.ru/item.asp?id=29962768.

PUSHKAREV,Y.V. - PUSHKAREVA, E.A. 2016. Fundamental knowledge in the context of the problems of lifelong learning and continuing education. In: Novosibirsk State Pedagogical University Bulletin, n. 1, pp. 87-98. (In Russian). Available online: https://elibrary.ru/item.asp?id=25581271.

SHIROBOKOV, S.N. 2012. Modern trends in the development of academic mobility of actors involved in educational process. In: Bulletin of Irkutsk State linguistic University, n. 4, pp. 201-211. (In Russian) Available online: https://elibrary.ru/item.asp?id=18689464. 
SIDORENKO, T.V. - RYBUSHKINA, S.V. 2015. Language education in Russian technical higher educational institutions: evolution, updating, prospects. In: Novosibirsk State Pedagogical University Bulletin, n. 1, pp. 20-29. (In Russian). Available online: https://elibrary.ru/item.asp?id=22943096

Words: 2713

Characters: 19732 (10,96 standard pages)

assoc. prof. Ekaterina A. Kostina

Novosibirsk State Pedagogical University

Novosibirsk

Russia

ea_kostina@mail.ru

prof. Dzhafar Mallaev

Dagestan State Pedagogical University

Makhachkala

Russia

vip.dgaf@mail.ru 